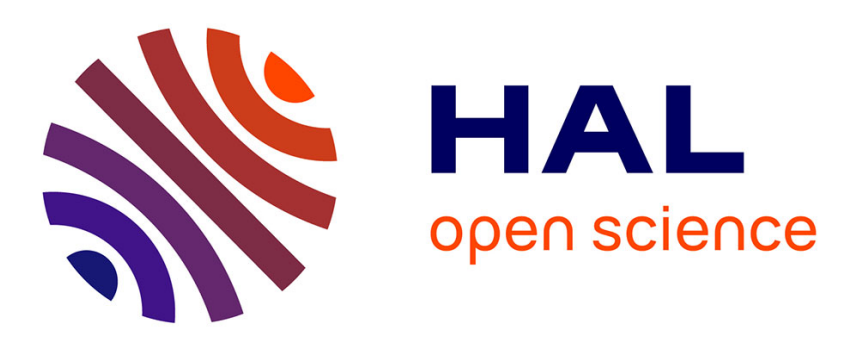

\title{
Method validation for the analysis of estrogens (including conjugated compounds) in aqueous matrices
}

\author{
Cecile Miege, P. Bados, C. Brosse, Marina Coquery
}

\section{To cite this version:}

Cecile Miege, P. Bados, C. Brosse, Marina Coquery. Method validation for the analysis of estrogens (including conjugated compounds) in aqueous matrices. Trends in Analytical Chemistry, 2009, 28 (2), p. 237 - p. 244 . 10.1016/j.trac.2008.11.005 . hal-00454542

\section{HAL Id: hal-00454542 \\ https://hal.science/hal-00454542}

Submitted on 8 Feb 2010

HAL is a multi-disciplinary open access archive for the deposit and dissemination of scientific research documents, whether they are published or not. The documents may come from teaching and research institutions in France or abroad, or from public or private research centers.
L'archive ouverte pluridisciplinaire HAL, est destinée au dépôt et à la diffusion de documents scientifiques de niveau recherche, publiés ou non, émanant des établissements d'enseignement et de recherche français ou étrangers, des laboratoires publics ou privés. 


\title{
Method validation for the analysis of estrogens (including conjugated compounds) in various aqueous matrices

\author{
C. Miège, P. Bados, C. Brosse, M. Coquery
} \\ Cemagref, Unité de recherche Qualité des Eaux et Prévention des Pollutions, 3 bis quai Chauveau, CP 220 - 69336 Lyon cedex 09, France \\ E-mail: cecile.miege@cemagref.fr
}

\begin{abstract}
Estrogens act as endocrine disruptors and are known to be discharged in the aquatic environment via effluents from wastewater treatment plants. Efficient analytical protocols are needed to identify and quantify estrogens in wastewaters and aquatic environments in order to study their sources, levels of exposure and modes of transfer. We developed and validated a new analytical method for estrogens in water. It allows to quantify five estrogenic hormones and their conjugated forms at the $\mathrm{ng} / \mathrm{L}$ level in rivers, wastewater treatment plant influents and effluents, with a satisfying precision (relative standard deviation of within-day analytical recoveries usually lower than 22\%). The method was statistically proven to be specific, thanks to the use of perdeuterated hormones as internal surrogates, which proved to be an efficient means to correct for matrix effects.
\end{abstract}

\section{Keywords}

Estrogens, conjugated forms, LC-MS/MS, environmental aqueous matrices, method validation

\section{Introduction}

Estrogens are a group of steroid hormones defined by their chemical structure. They can be defined by their effect in the estrous cycle. They act as endocrine disruptors, i.e. substances that interfere with the endocrine system and disrupt the physiologic function of hormones. During the last five decades, the consumption of estrogens for human medicine (i.e., for contraception, management of menopausal and post-menopausal syndrome, physiological replacement therapy in deficiency states and treatment of prostate and cancers) and animal farming (i.e., as growth promoters, developers of single-sex fish populations in aquaculture) has considerably increased. The presence of estrogenic compounds in surface waters has been reported since the early 80s [1]. Estrogens are usually not entirely metabolized and they reach the aquatic environment mainly via effluents from wastewater treatment plants (WWTP). The consequences of the presence of these substances in the aquatic environment are still largely unknown, but some negative impacts have been reported, for instance the feminization of fish in large rivers and some toxicological effects on wildlife [2,3]. The lack of knowledge on the toxicity and level of exposition of these compounds and their impact on 
ecosystems and human health has raised public concern about their occurrence in the environment. Thus, efficient analytical protocols are needed to identify and quantify these emerging contaminants in aquatics environments and to study their sources and modes of transfer.

Since 2001, 4 reviews [4-7] and at least 20 papers have been devoted to the development and validation of analytical protocols for estrogens in aqueous samples [e.g. 8-20]. These samples are mostly analysed by liquid or gas chromatography coupled with tandem mass spectrometry (LCMS/MS or GC-MS/MS). However, the use of the term "method validation" is often abusive [7]. Indeed, in a majority of these publications, linearity, limit of detection (LD) and limit of quantification (LQ) were estimated with standard solutions and rarely in real matrices. Therefore, the LD and LQ were probably often underestimated. Moreover, methods for the LD and LQ determination were seldom fully reported. Most of time, recoveries were only evaluated at a single level of spiking, even though they are known to vary with the level of spiking. In general, precision was not evaluated over several days and often it was not possible to determine if repeatability or reproducibility was tested. Matrix effects for real samples (i.e., specificity of the method) were not studied, whereas it is well known that they influence performances of analytical methods. Only 2 papers referred to the stability of estrogens concentrations in water samples and their conclusions remain contradictory on the stability of estradiol in surface waters [9,20]. Only 2 papers reported results of stability study in solvent extracts [12,15]. Finally, few papers took into account conjugated estrogens $[8,14,19,21]$, despite the fact that it is essential to measure the total quantity of estrogens including the conjugated fraction to assess accurately the concentrations and fluxes of estrogens in the aquatic environment.

In this study, we developed an analytical protocol for the determination of five estrogenic hormones (estrone [E1], 17 $\alpha$-estradiol [17 $\alpha$-E2], 17 $\beta$-estradiol [17 $\beta$-E2], 17 $\alpha$-ethynylestradiol [EE2] and estriol [E3]), including their conjugated forms, in various aqueous matrices (rivers, WWTP influents, WWTP effluents) using liquid chromatography coupled with tandem mass spectrometry (LC-MS/MS). In order to evaluate the total fraction of hormones (free and conjugated forms) and then to be able to measure the removal efficiency throughout WWTPs and the hormone fluxes from WWTP effluents entering into rivers, we chose to hydrolyse conjugated forms instead of identifying and quantifying them by means of LC-MS/MS. These 5 hormones were chosen because of their strong endocrine-disrupting potency in surface waters. Our analytical protocol was validated according to the French method validation standard NF XPT 90-210 (1999) [22]. The validation steps include the verification of linearity and the determination of the LQ in real matrices. Using real matrices, we also evaluated specificity (i.e., absence of matrix effects for various types of water 
samples), recoveries and precision (within and between days) of the whole method. In addition, we present results on the preservation of water samples and extracts, and on the efficiency of the hydrolysis step for the analysis of conjugated forms.

\section{Experimental section}

\subsection{Apparatus}

The LC system consisted on an Agilent 1100 (Agilent, Massy, France) coupled with an API 4000 with triple quadrupole mass spectrometer (Applied Biosystems-MDS Sciex, Courtaboeuf, France). Solid phase extractions were performed with an Autotrace workstation (Caliper Life Science, Roissy Charles de Gaulle, France). The hydrolysis of conjugated forms was performed with a Memmert incubator (Memmert, Schwabach, Germany).

\subsection{Materials and chemicals}

Glass fiber filter (GF/F, $0.7 \mu \mathrm{m}$ pore size) were obtained from Whatman (Versailles, France). We used OASIS ${ }^{\circledR}$ HLB cartridges, $200 \mathrm{mg}, 6 \mathrm{~mL}$ (Waters, Guyancourt, France) and Supelclean LC FLORISIL ${ }^{\circledR}$ cartridges, 1 g, 6 mL (Sigma Aldrich, St Quentin Fallavier, France) for extraction and clean-up. We used Xbridge Waters C18 endcaped column (150 mm x $2.1 \mathrm{~mm}$ x $3.5 \mu \mathrm{m}$ ) and guard column for chromatographic separation (Waters, Guyancourt, France). Methylene chloride, heptane, ethyl acetate, methanol, acetone of pesticide analysis grade, acetonitrile and ultrapure water (used for mobile phase) of HPLC grade were obtained from SDS (Val-De-Reuil, France). Acetic acid, pure at 98.9\%, was obtained from Sigma Aldrich (St Quentin Fallavier, France. Ultrapure water was obtained from a MilliQ water system (Millipore, St Quentin en Yvelines, France). Nitrogen of standard quality (industrial) was used for evaporation (Air Liquide, Pierre Bénite, France). Hormones (powder) (estrone [E1], $17 \beta$ and $\alpha$-estradiol [17 $\beta$ and $\alpha$-E2], $17 \alpha$-ethynylestradiol [EE2] and estriol [E3]) and conjugated hormones (powder) (estrone 3-sulfate [E1S], 17 $\beta$-estradiol 3-( $\beta$-Dglucuronide) $[17 \beta-E 2 G]$ and estriol 3-( $\beta$-D-glucuronide) $[E 3 G])$ were obtained from Sigma-Aldrich (Saint-Quentin Fallavier, France). Perdeuterated hormones (powder) (estrone-D4 [E1-D4], 17ßestradiol-D2 [17 $\beta$-E2-D2], 17 $\alpha$-ethynylestradiol-D4 [EE2-D4] and estriol-D2 [E3-D2])) and $\beta$ estradiol acetate were obtained from C.I.L. Cluzeau (Sainte-Foy-La-Grande, France). A crude solution of beta glucuronidase aryl sulfatase enzyme (Helix pomatia juice) was obtained from Sigma-Aldrich (Saint-Quentin Fallavier, France).

\subsection{Preparation before extraction}


Aqueous samples were filtered through pyrolyzed $\left(450^{\circ} \mathrm{C}, 1 \mathrm{~h}\right)$ glass fiber filter less than one day after sampling. Perdeuterated hormones (E1-D4, 17 $\beta$-E2-D2, 17 $\alpha$ EE2-D4 and E3-D2), used as internal surrogates, were spiked before the extraction step: at $125 \mathrm{ng} / \mathrm{L}$ in WWTP influents and 50 $\mathrm{ng} / \mathrm{L}$ in effluents or river waters.

\subsection{Extraction and clean-up protocols}

Sample volumes were $100 \mathrm{~mL}$ for influents and $250 \mathrm{~mL}$ for river waters and effluents. Extraction was performed on Oasis HLB cartridges as follows: after washing with $6 \mathrm{~mL}$ of methanol and $6 \mathrm{~mL}$ of ultrapure water, sample was percolated at $10 \mathrm{~mL} / \mathrm{min}$ and elution was achieved with $4 \mathrm{~mL}$ of a mixture ethyl acetate / methanol (70/30 - v/v), the extract was evaporated to dryness and reconstituted in a mixture of $1 \mathrm{~mL}$ of methylene chloride/heptane $(50 / 50, \mathrm{v} / \mathrm{v})$. Then, the extract was purified on Florisil as follows: after percolation of the extract at $10 \mathrm{~mL} / \mathrm{min}, 5 \mathrm{~mL}$ of a mixture of acetone/heptane $(75 / 25-\mathrm{v} / \mathrm{v})$ were used for elution, then evaporation to dryness was performed and the extract was reconstituted in $200 \mu \mathrm{L}$ of a mixture of water/acetonitrile $-60 / 40-\mathrm{v} / \mathrm{v}$ with $\beta$ estradiol acetate, used as internal standard, spiked at $40 \mu \mathrm{g} / \mathrm{L}$.

\subsection{Liquid chromatography and tandem mass spectrometry}

The injected volume was $10 \mu \mathrm{L}$. A gradient with LC grade water and acetonitrile (flow rate of 0.2 $\mathrm{mL} / \mathrm{min}$ ) was applied for the separation of the 5 hormones: $40 \%$ acetonitrile from 0 to 2 min, up to $80 \%$ acetonitrile at $4.5 \mathrm{~min}$ and until $15 \mathrm{~min}$. The column temperature was set at $35^{\circ} \mathrm{C}$.

Ionization was performed with an electrospray source in a negative mode and acquisition was achieved in Multiple Reaction Monitoring (MRM) mode (ion source temperature: $400{ }^{\circ} \mathrm{C}$, ion spray voltage: $4500 \mathrm{v}$, collision gas: 6 psi, curtain gas: 25 psi).

As recommended in the EU Commission Decision 2002/657/EC [23], the MS-MS conditions included the use of 2 ionization transitions for each compound (except for the perdeuterated surrogates), one for the quantification (QT) and one for the identity confirmation (CT). These transitions are reported in Table 1.

Final concentrations were calculated using recoveries obtained for the internal perdeuterated surrogates (17 $\alpha$-E2-D2 is corrected by $17 \beta-E 2-D 2)$. A chromatogram of a standard solution at $5 \mu \mathrm{g} / \mathrm{L}$ is presented on Figure 1.

\section{Table 1}




\section{Figure 1}

\subsection{Analysis of conjugated steroids}

As recommended by [24] for urine samples, the analysis of conjugated steroids was performed as follows: a fraction of the sample was submitted to enzymatic hydrolysis by beta glucuronidase aryl sulfatase from Helix pomatia $(1 / 1000-\mathrm{v} / \mathrm{v})$ at $\mathrm{pH} 5.2$ at $52^{\circ} \mathrm{C}$ during $15 \mathrm{~h}$. The sample was then extracted, purified and analysed as described for unconjugated forms. The conjugated forms concentration was deduced by subtracting concentration of free steroids (sample not submitted to hydrolysis before SPE) from concentration of total steroids (sample submitted to hydrolysis).

\subsection{Validation of the analytical method}

According to the French standard NF XPT 90-210 [22], linearity needs to be validated from standard solutions using Fisher statistic test with a risk $\alpha$ of $1 \%$. Linearity was tested on 7 concentration levels.

For the determination of the LQ, firstly they need to be evaluated and secondly they should be experimentally verified. A signal to noise ratio $(\mathrm{S} / \mathrm{N})$ of 10 was determined on calibration standards at 0.5 and $1 \mu \mathrm{g} / \mathrm{L}$. These instrumental LQ were corrected by analytical recoveries and concentration factors, which vary according to the matrix considered (e.g., 500 for a $100 \mathrm{~mL}$ sample). We added a security factor of 2 to compensate for the loss of sensitivity due to matrix effects in real samples, in order to obtain the "evaluated" LQ. Then, the LQ were verified by spiking real water samples at the concentration level of the "evaluated" LQ. The LQ is validated if: (LQ - $\left.\mathrm{C}_{\mathrm{LQ}}\right) /\left(\mathrm{s}_{\mathrm{LQ}} / \sqrt{\mathrm{n}}_{\mathrm{n}}\right)<10$ and $5 \mathrm{x}$ $\mathrm{s}_{\mathrm{LQ}}<\mathrm{LQ}$, with $\mathrm{C}_{\mathrm{LQ}}$ : the mean of measured concentrations of the spiked sample and $\mathrm{s}_{\mathrm{LQ}}$ : the standard deviation of the measured concentrations $(n=10)$. In our study, we evaluated the LQ with 5 replicates instead of 10 as recommended in the revised version of the French standard (2008). In the other French standard [22], the LD value is evaluated from LQ values however not verified. In our method, a result is mentioned as " $\angle \mathrm{LD}$ " when the concentration of the hormone of interest is below $\mathrm{S} / \mathrm{N}$ of 3 or when its presence cannot be confirmed by its 2 ionization transitions, as recommended in the EU Commission Decision 2002/657/EC [23].

Specificity (i.e., statistical evaluation for the verification of the absence of matrix effects according to [22]) should be tested using 10 samples of various aqueous matrices spiked at different levels of concentrations. In our case, we spiked 3 different types of matrices. For each molecule, the analytical method is considered specific if the regression curve $[($ analyzed concentration $)=f($ spiked 
concentration)] has (i) a slope not significantly different from 1 with the risk $\alpha$ of $1 \%$ and (ii) an origin ordinate not significantly different from 0 with the risk $\alpha$ of $1 \%$ (Student statistic tests).

Finally, trueness of the entire analytical method was tested through an interlaboratory trial organized by COST 636 (http://cost636xenobiotics.er.dtu.dk/) in October 2007.

\section{Results and discussion}

\subsection{Linearity of the analytical method}

The linearity of the method was statistically tested (Fisher-Snedecor test with $\mathrm{p}=0.01$ ). Acceptable linear responses were obtained for all 5 hormones using standard mixtures containing $0.5-80 \mu \mathrm{g} / \mathrm{L}$ of hormones in vials before injection, which correspond to concentration ranges from 1.0 to 200 $\mathrm{ng} / \mathrm{L}$ for influents and from 0.4 to $80 \mathrm{ng} / \mathrm{L}$ for effluents and river waters.

Linearity was also tested for the whole analytical method (including extraction and purification steps) on real water matrices. These results are reported in the paragraph on specificity of the analytical method.

When compared with other guidelines such as ICH (International Conference on Harmonisation of Technical Requirements for Registration of Pharmaceuticals for Human Use) [25] and IUPAC (International Union of Pure and Applied Chemistry) [26], principles to evaluate linearity are the same, however few details details are given on the statistical tests to be used. For IUPAC, a minimum of 6 concentration levels is recommended (instead of 5 for French standard and ICH), and more information on the calibration standard is given (range, replicates, random order). As for the French standard, it is also advised in the IUPAC guideline to statistically test linearity of calibration standards prepared in extracts from real matrices (to evaluate the matrix effect). No information on linearity is provided in the ISO (International Organization for Standardization) guideline [27].

\subsection{Limits of quantification $(L Q)$}

As explained in the experimental section, we obtained the instrumental LQ and evaluated the LQ for rivers, influents and effluents from chromatograms of standard solutions. These values are reported in Table 2. They range from 0.4 for E1 and $\alpha$-E2 to about $1.0 \mathrm{ng} / \mathrm{L}$ for EE2 in surface and effluent waters, and from 0.8 for $\alpha$-E2 to $3.0 \mathrm{ng} / \mathrm{L}$ for EE2 in influent waters, which is quite satisfying regarding the LQ reported in the literature. Indeed, in their review, Gabet et al. [7] reported LD (corresponding to $\mathrm{LQ} / 3$ ) in the order of $1 \mathrm{ng} / \mathrm{L}$ in wastewater, from 1 to $7 \mathrm{ng} / \mathrm{L}$ in influent, from 0.1 to $2.4 \mathrm{ng} / \mathrm{L}$ in effluent, and under $1 \mathrm{ng} / \mathrm{L}$ in surface water. 
As recommended in the French standard [22], we could verify these evaluated LQ by spiking river waters. We could not perform this verification for other sample types, as we need to obtain uncontaminated samples and we have not found influents nor effluents not contaminated with hormones. Nonetheless, we were able to confirm through the analyses of real matrices that the actual LQ for influent and effluent were comparable to those reported on Table 2.

However, this LQ determination for method validation lead to overestimated LQ. Indeed, the LQ reported in Table 2 are the worse we can obtain. For routine analyses, results are considered higher than the LQ when (i) the 2 ionization transitions (for the quantification and for the identity confirmation) are confirmed as explained in the EU Commission Decision 2002/657/EC [23] and (ii) the concentration value is within the range of the calibration curve.

\section{Table 2}

Other methods to evaluate LQ are reported in NF XPT 90-210 [22], ICH [25] and IUPAC [26] guidelines. They are based on visual evaluations (ICH), a signal-to-noise approach (ICH), the standard deviation of the blank (NF XPT 90-210, ICH, IUPAC), the calibration curve (NF XPT 90210, ICH) or the limit of detection (IUPAC). Only the French standard considers the necessity to verify the LQ by spiking real matrices. In the IUPAC guideline, it is advised not to use LQ and to evaluate the uncertainty of measurement for low concentrations (close to LD). No information on LQ is given in the ISO guideline [27].

\subsection{Recovery, repeatability and reproducibility of the extraction and purification steps}

Within-day recoveries and relative standard deviations (RSD) obtained for 5 replicate samples of surface water, WWTP influent and effluent are reported in Table 3. Average within-day recoveries generally ranged from 82 to $115 \%$ with RSD lower than $22 \%$, which is quite satisfying. We note only two exceptions: E3 in influent with average recovery of $75 \pm 36 \%$ and EE2 in effluent with average recovery of $128 \pm 4 \%$. Unspiked samples of tap, surface, WWTP effluent and influent waters were analysed in triplicate during an interlaboratory trial organized by COST 636 (http://cost636xenobiotics.er.dtu.dk/) in October 2007. Results showed that RSD of concentrations of E1, 17ß-E2, E3 and 17 $\alpha$-EE2 (17 $\alpha$-E2 not detected) were between 5 and $19 \%$.

We also determined between-days recoveries for a sampling period covering February to March 2007 for the 4 perdeuterated hormones in WWTP influents and effluents (3 WWTPs sampled, 3 different days of sampling per WWTP; i.e., 9 samples of influent and 9 samples of effluent). The 
results are illustrated on Figure 2. Between-days RSD ranged from 8 to $33 \%$ in influents and from 22 to $38 \%$ in effluents.

Repeatability correspond to RSD reported in Table 3 and reproducibility to RSD reported on Figure 2.

\section{Table 3}

\section{Figure 2}

In the ICH guideline [25], it is advised to test repeatability, intermediate precision (with evaluation of the effects of random events-under which the procedure is intended to be used- on the precision of the analytical procedure) and reproducibility. In the IUPAC guideline [26], it is recommended to test precision at least during a single series of analyses and precision under various series of analyses. Also, it is briefly mentioned that it can be useful to test effects of the operator, time and instrument. In the ISO guideline [27, chapters 2, 3 and 5], precision is treated very precisely considering repeatability and reproducibility in chapter 2 and 5, and intermediate precision in chapter 3 (with evaluation of the effect of time, operator, instrument and calibration). The precision of statistical tests is not taken into account in the ICH and IUPAC guidelines, however in depth details are provided in the ISO guideline.

\subsection{Specificity of the whole analytical method}

Specificity was tested using 10 aqueous samples (3 river waters, 3 WWTP influents and 4 WWTP effluents) spiked at different levels of concentrations (from 10 to $80 \mathrm{ng} / \mathrm{L}$ ). On Figure 3, we can verify that the regression curve $[($ analyzed concentration $)=\mathrm{f}($ spiked concentration $)]$ obtained for $\mathrm{E} 1$, after correction with E1-D2, is very close to the $\mathrm{y}=\mathrm{x}$ curve.

As explained in the experimental section (student tests on slope and origin ordinate), we verified specificity of our method for the 5 estrogenic hormones, which means that matrix effects are not significant. The use of perdeuterated hormones as internal surrogates appears to be an efficient method to correct for matrix effects.

\section{Figure 3}

To visualize matrix effect, we have reported on Figure 4 total ion chromatograms of mineral water, surface water, WWTP influent, WWTP effluent. 


\section{Figure 4}

In ICH guideline [25], the matrix effects evaluation entails the identification of compounds in real matrices and the verification of the absence of false positives (type I error) and false negatives (type II error). Special recommendations for appropriate chromatographic separations are briefly given (i.e. peak purity tests). In the IUPAC guideline [26], it is suggested to compare the slope of the calibration curve obtained with standards in solvent with the slope of the calibration curve obtained with standards in real matrix extracts. It is also advised to test a representative set of the matrices likely to be encountered, spiked in the appropriate range. No information on specificity nor matrix effect is given in the ISO guideline [27].

\subsection{Trueness of the whole analytical method}

Trueness is the degree of conformity of a measured quantity to its actual (true) value. The use of perdeuterated surrogates is a reliable way to ensure trueness of analyzed concentrations. To test the trueness of our method, we participated to an interlaboratory trial organized by COST 636 (http://cost636xenobiotics.er.dtu.dk/) in October 2007. Three hormones, E1, $\alpha$-E2 and EE2, were analysed by 8 to 11 laboratories using different analytical methods. Analyses were performed in triplicate in 1 standard solution and spiked and non-spiked real samples of 1 tap water, 1 surface water, 1 WWTP influent and 1 WWTP effluent. Performances of laboratories can be assessed by their Z-score (i.e., $Z=\frac{\bar{x}-\bar{X}}{\sigma}$, with $\bar{x}=$ mean of the replicate results of each laboratory, $\bar{X}=$ assigned value, $\sigma=$ standard deviation of the interlaboratory testing scheme). Results are considered satisfying if $|Z|<2$, questionable if $2 \leq|Z| \leq 3$, and unsatisfying if $|Z|>3$. For all samples, we obtained a $|Z|$-score lower than 1.8 which proves the trueness of our analytical method.

Various methods to evaluate trueness are reported in NF XPT 90-210 [22], ICH [25], IUPAC [26] and ISO [27] guidelines. They are based on (i) the determination of recoveries from certified or spiked matrices (ICH, IUPAC, ISO), (ii) the comparison with a second well-characterized analytical protocol (NF XPT 90-210, ICH, IUPAC), (iii) interlaboratory assays (ISO). In the ISO guideline [27, chapter 4], trueness is particularly detailed providing information on experiments to perform, statistical tests and results interpretation.

\subsection{Recovery and repeatability of hydrolysis of conjugated forms}


We tested the efficiency of our hydrolysis method for 3 conjugated hormones: estrone 3-sulfate [E1S], 17 $\beta$-estradiol 3-( $\beta$-D-glucuronide) [17 $\beta$-E2G] and estriol 3-( $\beta$-D-glucuronide) [E3G]). Samples of influent, effluent and river waters were spiked in triplicates with $20 \mathrm{ng} / \mathrm{L}$, except for 17ß-E2G in WWTP effluents spiked at $40 \mathrm{ng} / \mathrm{L}$. Hydrolysis recoveries (R) and RSD are reported in Table 4 , they range from $85 \pm 9 \%$ for $\mathrm{E} 3 \mathrm{G}$ in river waters to $110 \pm 2 \%$ for $17 \beta$-E2G in WWTP effluents. These results are all the more satisfying since they include losses during extraction and purification steps.

\subsection{Extracts and samples preservation}

We studied the stability of the 5 estrogens in solvent at 2 different steps of our analytical protocol: after solid-phase extraction on OASIS HLB $(n=2)$ and in concentrated extracts before LC-MS/MS analyses $(n=3)$. Using statistical tests of mean comparison between initial and final concentrations (t-tests, $\mathrm{p}=0.001$ ), we concluded that no degradation occurred (i) in the SPE extracts ( $4 \mathrm{~mL}$ of a mixture ethyl acetate / methanol, 70/30, v/v) stored for 3 days at room temperature, and (ii) in vials before injection (in $200 \mu \mathrm{L}$ of a mixture of water/acetonitrile, 60/40, v/v) stored for 30 days at $18^{\circ} \mathrm{C}$.

We also studied the stability of the 5 hormones in a duplicate sample of filtered WWTP influent spiked at around $40 \mathrm{ng} / \mathrm{L}$, which was stored at $4{ }^{\circ} \mathrm{C}$ during 1, 3 and 6 days. We observed a decrease of the concentrations of all studied hormones of about $5 \%$ per day. From the literature, we know that the degree of degradation can vary from one water sample to the next. Indeed, concerning surface waters stored at $4^{\circ} \mathrm{C}$, Baronti et al. [20] reported "severe" losses of E2 (exact value not reported) after 7 days storage, whereas Vanderford et al. [9] obtained only 15\% losses of E2 after 14 days storage. Thus, we decided that samples must be analyzed within $24 \mathrm{~h}$ after sampling and filtration steps.

\section{Conclusion}

Our analytical protocol allows quantifying 5 estrogenic hormones and their conjugated forms at the ng/L level in rivers, WWTP influents and WWTP effluents with typically satisfying recoveries, from 82 to $115 \%$ and repeatability lower than $22 \%$ for all matrices. We could also estimate reproducibility over a 2 months period of sampling, which was below 33\% in influent and 38\% in effluent. The method was statistically proven to be specific thanks to the use of perdeuterated hormones as internal surrogates, which is an efficient means to correct for matrix effects in complex water samples. 
We are now applying this method on several WWTP over France in order to determine influent and effluent concentrations and to calculate efficiency of treatment for different processes.

\section{Acknowledgements}

This study was supported by the French National Research Agency (ANR), as part of the Amperes project and by the Water Agency Rhône Méditerrannée \& Corse. We thank J.M. Choubert and V Gabet (Cemagref) for WWTP sampling and help for sample analyses.

\section{References}

[1] M.L. Richardson, J.M. Bowron, J. Pharm. Pharmacol. 37 (1985) 1.

[2] B. Halling-Sorensen, S.N. Nielsen, P.F. Lanzky, F. Ingerslev, H.C.H. Lutzhoft, S.E. Jorgensen, Chemosphere 36 (1998) 357.

[3] M.Y. Gross-Sorokin, S.D. Roast, G.C. Brighty, Environ. Health Persp. 114 (2006) 147.

[4] R.L. Gomes, M.D. Scrimshaw, J.N. Lester, Trend Anal. Chem. 22 (2003) 697.

[5] M. Petrovic, E. Eljarrat, M.J.L. de Alda, D. Barcelo, J. Chromatogr. A 974 (2002) 23.

[6] M.J.L. de Alda, D. Barcelo, Fresen. J. Anal. Chem. 371 (2001) 437.

[7] V. Gabet, C. Miège, P. Bados, M. Coquery. Trend Anal. Chem 26:11 (2007) 1113.

[8] P. Labadie, H. Budzinski, Environ. Sci. Technol. 39 (2005) 5113.

[9] B.J. Vanderford, R.A. Pearson, D.J. Rexing, S.A. Snyder, Anal. Chem. 75 (2003) 6265.

[10] R.A. Trenholm, B.J. Vanderford, J.C. Holady, D.J. Rexing, S.A. Snyder, Chemosphere 65 (2006) 1990.

[11] M.D. Hernando, M. Mezcua, M.J. Gomez, O. Malato, A. Aguera, A.R. Fernandez-Alba, J. Chromatogr. A 1047 (2004) 129.

[12] T. Benijts, W. Lambert, A. De Leenheer, Anal. Chem. 76 (2004) 704.

[13] A. Lagana, A. Bacaloni, I. De Leva, A. Faberi, G. Fago, A. Marino, Anal. Chim. Acta 501 (2004) 79.

[14] A. Mouatassim-Souali, S.L. Tamisier-Karolak, D. Perdiz, M. Cargouet, Y. Levi, J. Sep. Sci. 26 (2003) 105.

[15] H. Noppe, K. De Wasch, S. Poelmans, N. Van Hoof, T. Verslycke, C.R. Janssen, H. De Brabander, Anal. Bioanal. Chem. 382 (2005) 91.

[16] J. Carpinteiro, J.B. Quintana, I. Rodriguez, A.M. Carro, R.A. Lorenzo, R. Cela, J. Chromatogr. A 1056 (2004) 179.

[17] H. Noppe, T. Verslycke, E. De Wulf, K. Verheyden, E. Monteyne, P. Van Caeter, C.R. Janssen, H.F. De brabander, Ecotox. Environ. Safe. 66 (2007) 1.

[18] S. Zuehlke, U. Duennbier, T. Heberer, J. Sep. Sci. 28 (2005) 52.

[19] T. Isobe, H. Shiraishi, M. Yasuda, A. Shinoda, H. Suzuki, M. Morita, J. Chromatogr. A 984 (2003) 195. 
[20] C. Baronti, R. Curini, G. D'Ascenzo, A. Di Corcia, A. Gentili, R. Samperi, Environ. Sci. Technol. 34 (2000) 5059.

[21] A. Gentili, D. Perret, S. Marchese, R. Mastropasqua, R. Curini and A. Di Corcia, Chromtagraphia 56 (2002) 25.

[22] AFNOR, Norme NF XPT 90-210, Protocole d'évaluation d'une méthode alternative d'analyse physico-chimique par rapport à une méthode de référence (1999), 58p

[23] EU COMMISSION DECISION of 12 August 2002 implementing Council Directive 96/23/EC concerning the performance of analytical methods and the interpretation of results (2002/657/EC), $29 \mathrm{p}$

[24] B. Lebizec, M.-P. Montrade, F. Monteau, F. André, Anal. Chim. Acta, 275 (1993) 123.

[25] ICH Harmonised tripartite guideline, Validation of analytical procedures: text and methodology Q2 (R1), current step version 4 (2005), (13p)

[26] M. Thompson, S.L.R. Ellison, R. Wood, IUPAC, Harmonized guidelines for single-laboratory validation of methods of analysis, Pure Appl. Chem. 74/5 (2002) 835 (21p)

[27] AFNOR, Norme ISO 5725, chapters 1-6, Exactitude (justesse et fidélité) des résultats et méthodes de mesure, (1994) 213p 


\section{Tables}

Table 1: Ionization transitions used for the quantification (QT) and for the identity confirmation (CT) of hormones and perdeuterated surrogates.

\begin{tabular}{lll}
\hline Analyte & QT & CT \\
\hline E1 & $268.9-145.2$ & $268.9-142.9$ \\
$17 \alpha$ and $\beta$-E2 & $270.9-145.1$ & $270.9-182.9$ \\
E3 & $287.1-145.2$ & $287.1-171.0$ \\
& & \\
$17 \alpha-E E 2$ & $294.4-145.1$ & $294.4-158.9$ \\
& & $313.1-144.8$ \\
$\beta$-E2 acetate & $313.1-253.0$ & \\
E1-D4 & $273.0-147.0$ & \\
$17 \beta-E 2-D 2$ & $273.0-185.0$ & \\
E3-D2 & $289.3-147.0$ & \\
$17 \alpha-E E 2-D 4$ & $299.2-147.0$ & \\
\hline
\end{tabular}

Table 2: Limits of quantification (LQ) for the 5 hormones.

\begin{tabular}{|c|c|c|c|c|c|}
\hline \multirow[b]{2}{*}{ Hormones } & \multicolumn{2}{|c|}{ Instrumental LQ } & \multicolumn{3}{|c|}{ LQ in real matrices $(\mathrm{ng} / \mathrm{L})$} \\
\hline & (pg injected) & $(\mu \mathrm{g} / \mathrm{L}$ in extract) & In river water ${ }^{1}$ & In influent ${ }^{2}$ & In effluent ${ }^{2}$ \\
\hline E1 & 2.5 & 0.25 & 0.4 & 1.0 & 0.4 \\
\hline $17 \alpha-E 2$ & 1.5 & 0.15 & 0.4 & 0.8 & 0.4 \\
\hline $17 \beta-\mathrm{E} 2$ & 3.0 & 0.3 & 0.6 & 1.4 & 0.6 \\
\hline E3 & 5.0 & 0.5 & 0.8 & 2.6 & 0.8 \\
\hline EE2 & 7.0 & 0.7 & 1.2 & 3.0 & 1.2 \\
\hline
\end{tabular}

${ }^{\mathrm{T}}$ : verified by $\mathrm{n}=5$ spiking (see text for explanation)

${ }^{2}$ : not verified by spiking because these matrices are naturally contaminated with hormones 
Table 3: Within-day average recoveries $(\mathrm{R}, \%, \mathrm{n}=5)$ and relative standard deviation $(\mathrm{RSD}, \%)$ for the 5 hormones in river water, WWTP influent and effluent.

\begin{tabular}{|c|c|c|c|c|c|c|c|c|c|c|c|c|}
\hline \multirow{3}{*}{ Hormones } & \multicolumn{4}{|c|}{ River water } & \multicolumn{4}{|c|}{ WWTP influent } & \multicolumn{4}{|c|}{ WWTP effluent } \\
\hline & \multicolumn{2}{|c|}{$\begin{array}{l}\text { Spiking conc. } \\
10 \mathrm{ng} / \mathrm{L}\end{array}$} & \multicolumn{2}{|c|}{$\begin{array}{l}\text { Spiking conc. } \\
40 \mathrm{ng} / \mathrm{L}\end{array}$} & \multicolumn{2}{|c|}{$\begin{array}{l}\text { Spiking conc. } \\
20 \mathrm{ng} / \mathrm{L}\end{array}$} & \multicolumn{2}{|c|}{$\begin{array}{l}\text { Spiking conc. } \\
80 \mathrm{ng} / \mathrm{L}\end{array}$} & \multicolumn{2}{|c|}{$\begin{array}{l}\text { Spiking conc. } \\
15 \mathrm{ng} / \mathrm{L}\end{array}$} & \multicolumn{2}{|c|}{$\begin{array}{l}\text { Spiking conc. } \\
60 \mathrm{ng} / \mathrm{L}\end{array}$} \\
\hline & $\mathrm{R}$ & RSD & $\mathrm{R}$ & RSD & $\mathrm{R}$ & RSD & $\mathrm{R}$ & RSD & $\mathrm{R}$ & RSD & $\mathrm{R}$ & RSD \\
\hline E1 & 87 & 3 & 106 & 6 & 115 & 19 & 84 & 8 & 112 & 11 & 110 & 4 \\
\hline $17 \alpha-\mathrm{E} 2$ & 91 & 9 & 88 & 8 & $105^{1}$ & 22 & 106 & 6 & 100 & 7 & 97 & 4 \\
\hline $17 \beta-E 2$ & 84 & 8 & 89 & 5 & 103 & 21 & 95 & 11 & 95 & 10 & 96 & 4 \\
\hline EE2 & 82 & 10 & 110 & 20 & 96 & 21 & 105 & 15 & 105 & 16 & 128 & 4 \\
\hline E3 & 88 & 14 & 104 & 5 & 91 & 17 & 75 & 36 & 111 & 12 & 97 & 7 \\
\hline
\end{tabular}

${ }^{1}$ : native concentration of $\alpha$-E2 was quantified but not confirmed.

Table 4: Hydrolysis recoveries ( $\mathrm{R}, \%, \mathrm{n}=3$ ) and relative standard deviation (RSD, \%) for the 3 conjugated estrogens in river water, WWTP influent and effluent spiked at $20 \mathrm{ng} / \mathrm{L}$.

\begin{tabular}{lllllll} 
& River water & \multicolumn{2}{c}{ WWTP influent } & \multicolumn{2}{c}{ WWTP effluent } \\
& R & RSD & R & RSD & R & RSD \\
E1S & 87 & 3 & 89 & 16 & 87 & 1 \\
$17 \beta-E 2 G$ & 95 & 13 & $104^{1}$ & 13 & 110 & 2 \\
E3G & 85 & 9 & 97 & 16 & 99 & 5
\end{tabular}

${ }^{1}$ : spiking at $40 \mathrm{ng} / \mathrm{L}$. 


\section{Figures}

Intensity (cPs)

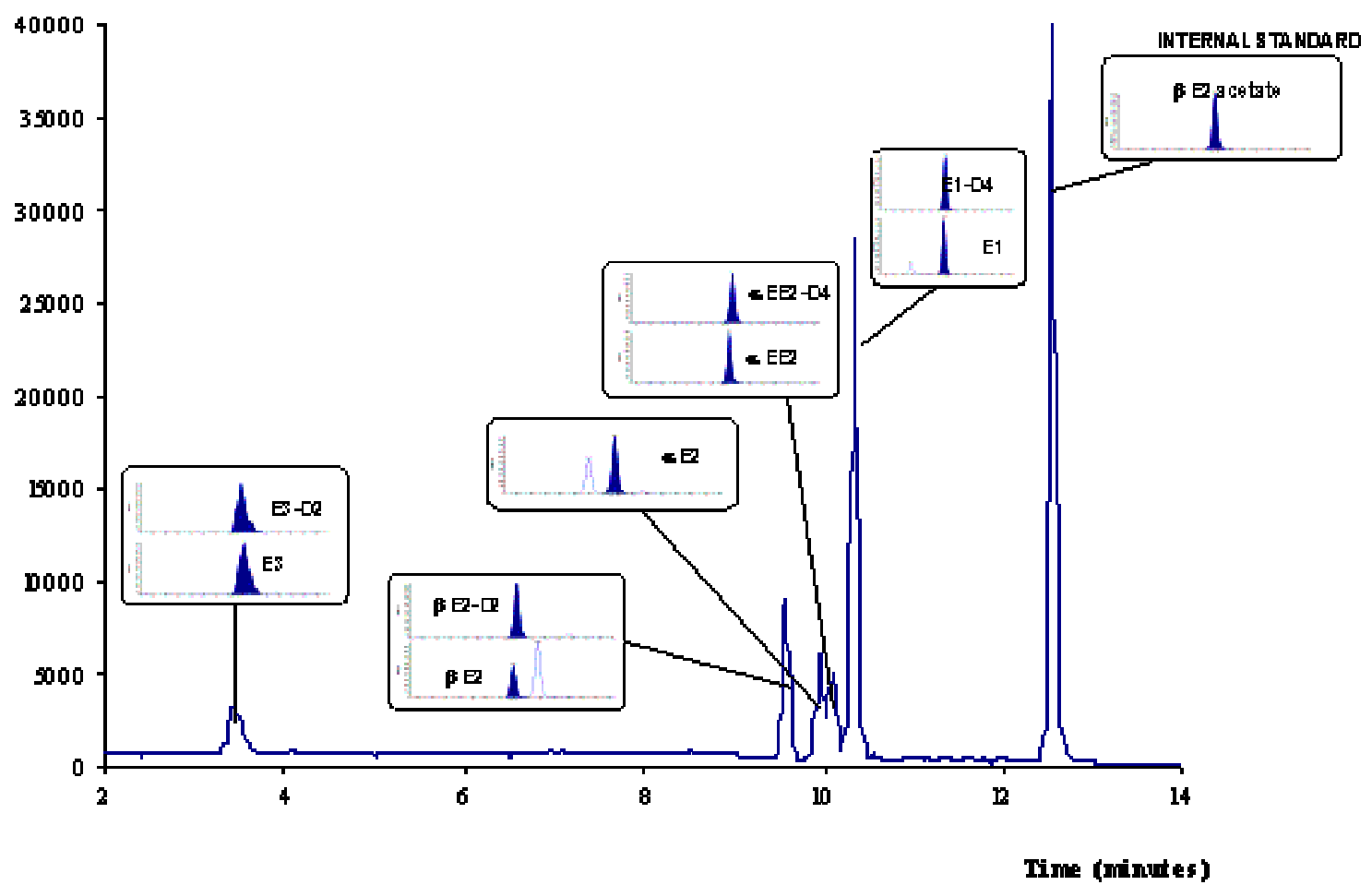

Figure 1: Chromatogram of a standard solution at $5 \mu \mathrm{g} / \mathrm{L}$.

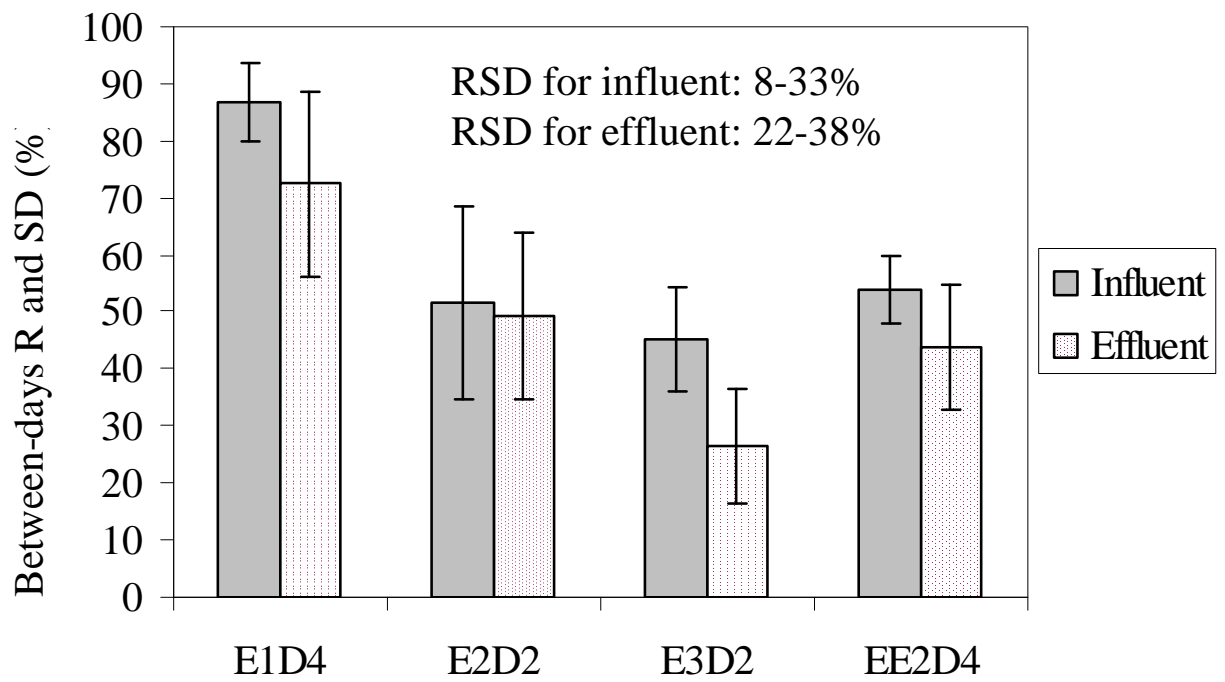

Figure 2: Between-days average recoveries (R, \%), standard deviation (SD, \%) and relative standard deviation (RSD, \%) for the 4 perdeuterated hormones in 9 influents and 9 effluents ; 3 WWTPs sampled, 3 different days of sampling per WWTP, sampling period covering February to March 2007. 


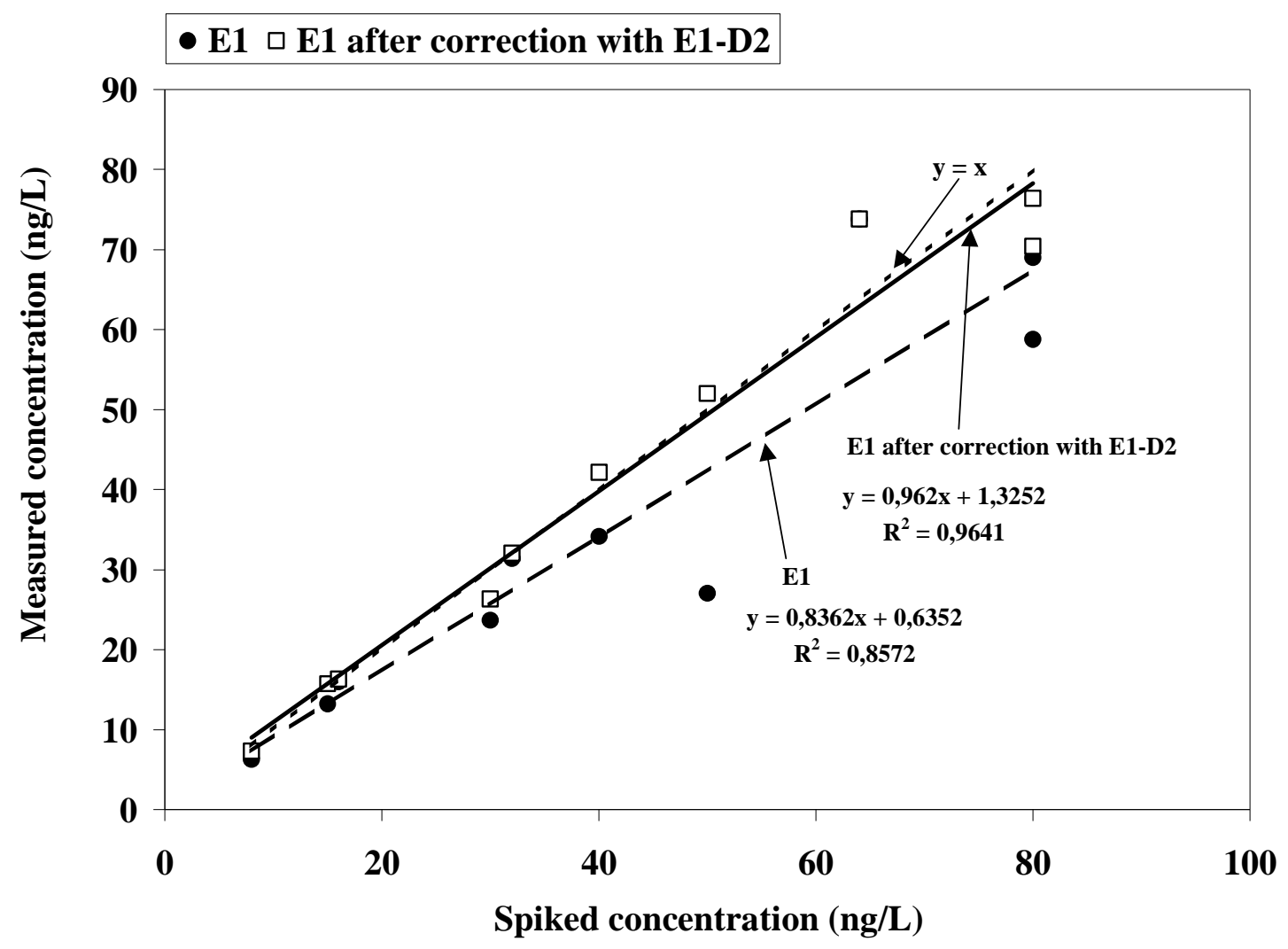

Figure 3: Specificity of the method for E1: tested on 3 river waters, 3 WWTP influents and 4 WWTP effluents spiked at concentrations from 10 to $80 \mathrm{ng} / \mathrm{L}$. 

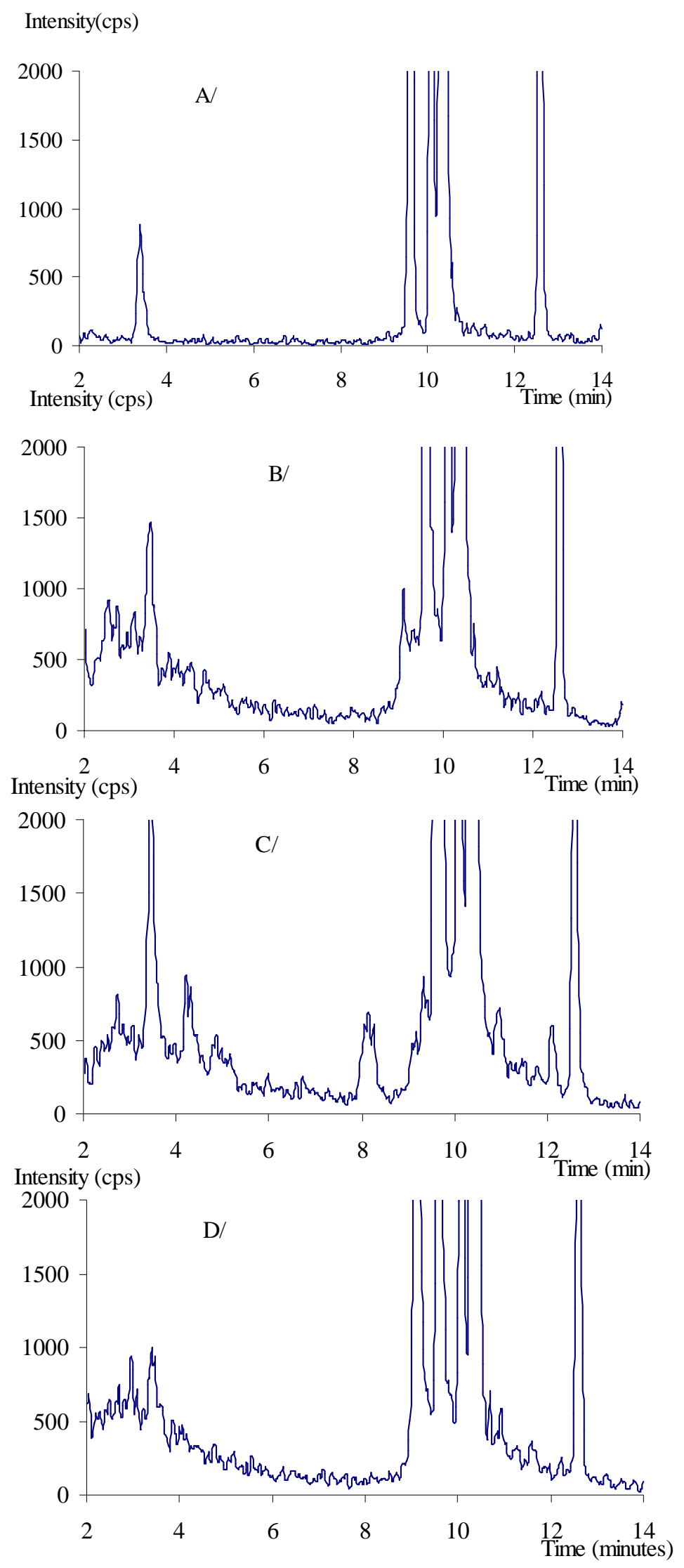

Figure 4: Total ion chromatograms of A/ Mineral water, B/ Surface water, C/ WWTP influent, D/ WWTP

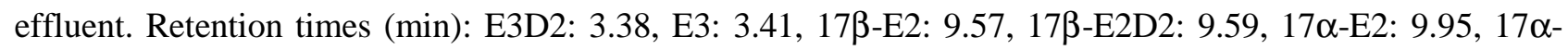
EE2D4: 10.08, 17 $\alpha$-EE2: 10.12, E1D4: 10.33, E1: 10.36, $\alpha$-E2acetate: 12.57. 